\title{
Current perspectives on bisphosphonate treatment in Paget's disease of bone
}

This article was published in the following Dove Press journal:

Therapeutics and Clinical Risk Management

20 November 2014

Number of times this article has been viewed

\author{
Winnie Zee Man Wat \\ Department of Medicine, Pamela \\ Youde Nethersole Eastern Hospital, \\ Chai Wan, Hong Kong
}

\begin{abstract}
Paget's disease of bone is a chronic metabolic bone disease with focal increase in bone turnover. The exact etiology of the disease is uncertain, although genetic and environmental factors are believed to be important. Bisphosphonate is the main class of medication being used to control disease activity via its antiresorptive effect. This review discusses the controversies concerning the use of bisphosphonates in the treatment of Paget's disease of bone, the efficacy of different bisphosphonates in controlling disease activity, and the possible rare side effects of bisphosphonates. Symptoms are the main indication for treatment in Paget's disease of bone. As treatment benefits in asymptomatic individuals remain controversial and nonevidence based, the decision to treat these patients should be individualized to their risk and benefit profiles. There are several trials conducted to evaluate and compare the efficacy of different regimes of bisphosphonates for treating Paget's disease of bone. Most trials used biochemical markers rather than clinical symptoms or outcomes as parameters for comparison. Zoledronate is an attractive option as it can achieve high rates of biochemical remission and sustain long duration of suppression by a single dose. Atypical femoral fracture and osteonecrosis of the jaw are two rare and severe side effects reported, possibly related to the use of bisphosphonates in patients with osteoporosis and malignancy-induced hypercalcemia. As the regimes of bisphosphonates used for treating Paget's disease of bone are different from those two diseases, the risks of developing these two possible side effects are expected to be very low, although this remains unknown. Vitamin D and calcium supplement should be given to patients at risk of vitamin D insufficiency when given zoledronate, as symptomatic hypocalcemia may develop. For those intolerant of bisphosphonates, subcutaneous calcitonin can be used for a limited period due to its associated risk of malignancy.
\end{abstract}

Keyword: osteitis deformans, antiresorptive, alkaline phosphatase

\section{Paget's disease of bone}

Paget's disease of bone is a chronic metabolic bone disorder that is characterized by focal areas of accelerated remodeling activity, which results in rapid bone resorption and excessive yet disorganized bone formation. ${ }^{1}$ It is usually diagnosed radiologically by its characteristic features of coarsening of bone trabeculae with focal osteosclerosis, cortical thickening, and bone enlargement. Typical histology of the lesion reveals a mosaic of woven and lamellar bone, with the bone marrow being replaced by peritrabecular fibrosis and capillary ingrowth. ${ }^{2}$ The elevated serum total alkaline phosphatase (ALP), due to prevailing osteoblasts activity, reflects the extent and activity of the disease. Single or multiple bones can be affected by the disease, and the typical sites of involvement include pelvis, femur, lumbar spine, skull, and tibia. ${ }^{3-8}$ The bone at the lesion is typically formed in a chaotic manner and is usually mechanically insufficient and at risk of deformity and fracture.
Correspondence: Winnie Zee Man Wat Department of Medicine, Pamela Youde Nethersole Eastern Hospital, 3 Lok Man Road, Chai Wan, Hong Kong

Tel +852 2595 6I I I

Email watzm@ha.org.hk 
As yet, the exact etiology of the disease has not been well elucidated, and the speculation of it being triggered by viral infection has not been fully validated by studies. ${ }^{9-14}$ Genetic studies over the past decades have revealed that Sequestosome 1 (SQSTM1), encoding the scaffold protein $\mathrm{p} 62$, is the most common gene associated with increased risk of Paget's disease of bone. ${ }^{15-17}$ Mutations of this gene were found in $20 \%-50 \%$ of familial cases and in about $5 \%-10 \%$ of sporadic cases. ${ }^{18}$ The role that it plays in the pathogenesis of the disease, however, remains unclear. This disease typically manifests after middle age, and the extremely rare form of juvenile Paget's disease that presents in childhood is due to osteoprotegerin deficiency and is now considered another disease entity. ${ }^{19}$ For unknown reason, there is great discrepancy in the prevalence and incidence of the disease among different ethnic groups. The disease is common in the UK, Australia, North American, and Western Europe but is very rare in North Europe, Asia, and Africa. ${ }^{20-22}$ Some epidemiological data also revealed a fall in prevalence and clinical severity of the disease in developed countries, which is postulated due to changes in ethnic constitution of the population or in environmental triggers. ${ }^{23,24}$

\section{Controversy on the use of bisphosphonates in treating Paget's disease of bone}

Nitrogen-containing bisphosphonates are among the first line medications being used to treat Paget's disease of bone. They suppress disease activity by reducing osteoclast-mediated bone resorption and bone turnover, which is reflected by the reduction or normalization of the raised serum ALP level.

Symptoms are the main indication for treating Paget's disease of bone. They include localized pain at lesion, neurological symptoms due to deformity of vertebrae compressing on the cord or nerves, Pagetic hearing loss, high output heart failure due to extensive skeletal involvement, and hypercalcemia related to immobilization. Bisphosphonates are also recommended to be used before orthopedic intervention to the involved bone to possibly reduce blood loss. ${ }^{25,26}$

In contrast to the situation in symptomatic cases, there has long been controversy on whether bisphosphonates given with the intention to reduce risk of developing complications in relation to disease progression is indicated or beneficial in asymptomatic cases. This issue is of particular importance as the majority of patients are asymptomatic. Based on the fact that untreated pagetic lesions may expand progressively with a reported rate of about $1 \mathrm{~cm} /$ year, ${ }^{27}$ some experts advocate the use of bisphosphonates in asymptomatic patients with lesions at sites that are likely to cause complications, such as skull, spine, weight bearing long bones, adjacent to large joints, and jaw.

Recently, a large randomized trial, Paget's disease of bone: a randomized trial of intensive versus symptomatic management (PRISM) study, ${ }^{28}$ was conducted to compare the effects of symptomatic treatment with intensive bisphosphonates therapy in 1,324 patients with Paget's disease of bone, with a median follow-up period of 3 years (ranging from 2 to 5 years). The symptomatic treatment group was treated only if they had pagetic bone pain, for which they were first given analgesics or anti-inflammatory drugs, followed by bisphosphonates if not responding. On the other hand, the intensive group received repeated courses of bisphosphonates irrespective of symptoms, with the aim of reducing and maintaining serum ALP levels within the normal range. The endpoints were quality of life, bone pain, hearing thresholds, fracture, and orthopedic surgery. As expected, the mean serum ALP level was significantly lower within 4 months of commencing treatment in the intensive treatment group than in the symptomatic treatment group and remained lower throughout the study $(P<0.001)$.

In spite of that, there were no significant differences identified in quality of life, overall bodily pain, or in pagetic bone pain between the groups. Similarly, hearing thresholds, as assessed by audiometry, did not change significantly and did not differ between the treatment groups. Furthermore, there was no significant difference both in the incidence of clinical fractures and in the number of orthopedic surgery required between the two groups. Clinical fractures occurred in 46 of 661 patients $(7.0 \%)$ in the intensive treatment group as compared with 49 of 663 patients $(7.4 \%)$ in the symptomatic treatment group, and orthopedic surgery was required in 50 of 661 patients $(7.3 \%)$ in the former and in 55 of 663 patients $(8.3 \%)$ in the latter. It was concluded by the investigators that aiming to maintain normal ALP levels with intensive bisphosphonate therapy conferred no clinical advantage over symptom-driven management in patients with established Paget's disease of bone.

Although several limitations of the PRISM study were recognized, including the fractures counted might not have involved Pagetic bone, $75 \%$ of the subjects were not treatment naive, the relatively short follow-up period for this chronic illness, and the limited choice of bisphosphonates, ${ }^{29}$ the findings of such a large, randomized trial does shed some light on the appropriate treatment aim of the disease. It seems that liberal use of bisphosphonates, aiming to gain biochemical normalization of serum ALP, conveys 
marginal clinical benefits over symptomatic treatment in most cases. Hence, in asymptomatic cases, the decision to treat or not should be based on clinical judgment of the patient's individual risk and benefit profile and consideration of patient's preference.

Currently, there is an ongoing multicenter, double blind, randomized, controlled trial, the Zoledronate in the Prevention of Paget's (ZiPP) study, which investigates whether treatment with zoledronic acid in individuals carrying mutations in SQSTM1 can prevent the development of Paget's disease of bone as defined by new bone lesion. ${ }^{30}$ The results of such a trial is expected to draw more discussion on the approach of prophylactic treatment in subjects genetically predisposed to Paget's disease of bone.

\section{Comparison of different bisphosphonates in controlling active Paget's disease of bone}

Bisphosphonates are analogs of inorganic pyrophosphate, which is a ubiquitous metabolite in all tissues. They bind avidly to the calcium/phosphate inorganic mineral phase of bone and are not hydrolyzed by pyrophosphatases such as bone ALP and, hence, have a sustained effect on reducing bone resorption. As the older generation of bisphosphonates such as etidronate may result in osteomalacia, aminobisphosphonates and nitrogen-containing bisphosphonates were subsequently developed. In contrast to the older bisphosphonates, nitrogen-containing bisphosphonates act differently by inhibiting farnesyl diphosphate synthase, an enzyme in the mevalonate pathway that is critical in the prenylation of small G-proteins, which mediates cytoskeletal rearrangement in osteoclasts. ${ }^{31}$ The newer generation of bisphosphonates include alendronate, ibandronate, pamidronate, risedronate, and zoledronic acid.

There have been several comparative trials conducted to evaluate the efficacy of different bisphosphonates for treating Paget's disease of bone. Most trials use biochemical markers rather than symptoms or clinical outcomes as parameters for comparison. It should be noted that biochemical remission may not necessarily transfer to potential clinical benefits or outcomes, especially when the disease activity is low or the patient is asymptomatic. In addition, other concomitant diseases such as vitamin D insufficiency that may affect the ALP level should be excluded before using it as the parameter for assessing disease activity. In the majority of studies, therapeutic response is defined as normalization of serum total ALP or suppression of excess total ALP by more than $75 \%$, as shown in Table 1 .
The oldest bisphosphonate being used to treat Paget's disease of bone is etidronate. It is now rarely used due to its side effect of inducing osteomalacia and its relative weak antiresorptive effect. Small studies have shown that alendronate and risedronate could achieve a higher remission rate than etidronate. ${ }^{32,33}$ Pamidronate is another relatively old bisphosphonate, that has been given intravenously to treat the disease for decades. Data has shown that acquired resistance could develop in subjects with repeated courses of pamidronate treatment and resulted in progressive reduction in responsiveness. Such phenomenon is usually observed in patients with extensive Paget's disease of bone, and the underlying mechanism is not well understood. It seems that such acquired resistance is specific to pamidronate, as it has been rarely reported to occur with other nitrogen-containing bisphosphonates. ${ }^{34}$

A small comparative study on treatment-naive patients has shown that oral alendronate ( $40 \mathrm{mg} /$ day for 3 months) and intravenous pamidronate ( $60 \mathrm{mg}$ every 3 months), given until normalization of serum total ALP, were able to achieve biochemical remission in $86 \%$ and $56 \%$ of patients, respectively, in 1 year. It seems that oral alendronate is more effective to achieve biochemical remission by this regime comparison. ${ }^{35}$ The crossover of drug use in this study also showed that, among those who were unable to achieve biochemical remission after 1 year of pamidronate treatment, 10/14 (71\%) patients were able to attain that with alendronate treatment. ${ }^{35}$

Several trials compare the efficacy of zoledronic acid and pamidronate in achieving biochemical remission. One study has shown that one dose of intravenous zoledronic acid $4 \mathrm{mg}$ could render $93 \%$ of patients to achieve normal serum total ALP after 6 month, while only 35\% for those receiving intravenous pamidronate $60 \mathrm{mg}$ every 3 months. ${ }^{36}$ The crossover part of that study has shown that either a single dose of neridronate or zoledronate infusion could normalize serum total ALP in more than $80 \%$ of patients in whom pamidronate had failed to achieve that. ${ }^{36}$ In another trial, a single dose of $5 \mathrm{mg}$ zoledronic acid normalized the serum total ALP in $89 \%$ of patients after 6 months compared to only $58 \%$ receiving the regime of oral risedronate $30 \mathrm{mg}$ daily for 60 days. ${ }^{37} \mathrm{~A}$ follow-up study of that cohort revealed that $98 \%$ of zoledronate-treated patients who were in remission at 6 months posttreatment remained so at 2 years posttreatment, as compared to $57 \%$ for risedronate-treated individuals, ${ }^{38}$ at 5-6 years posttreatment, the biochemical remission rates were $87 \%$ and $38 \%$, respectively. ${ }^{39}$

Table 1 summarizes the findings of recent comparative studies on the efficacy of different bisphosphonates 


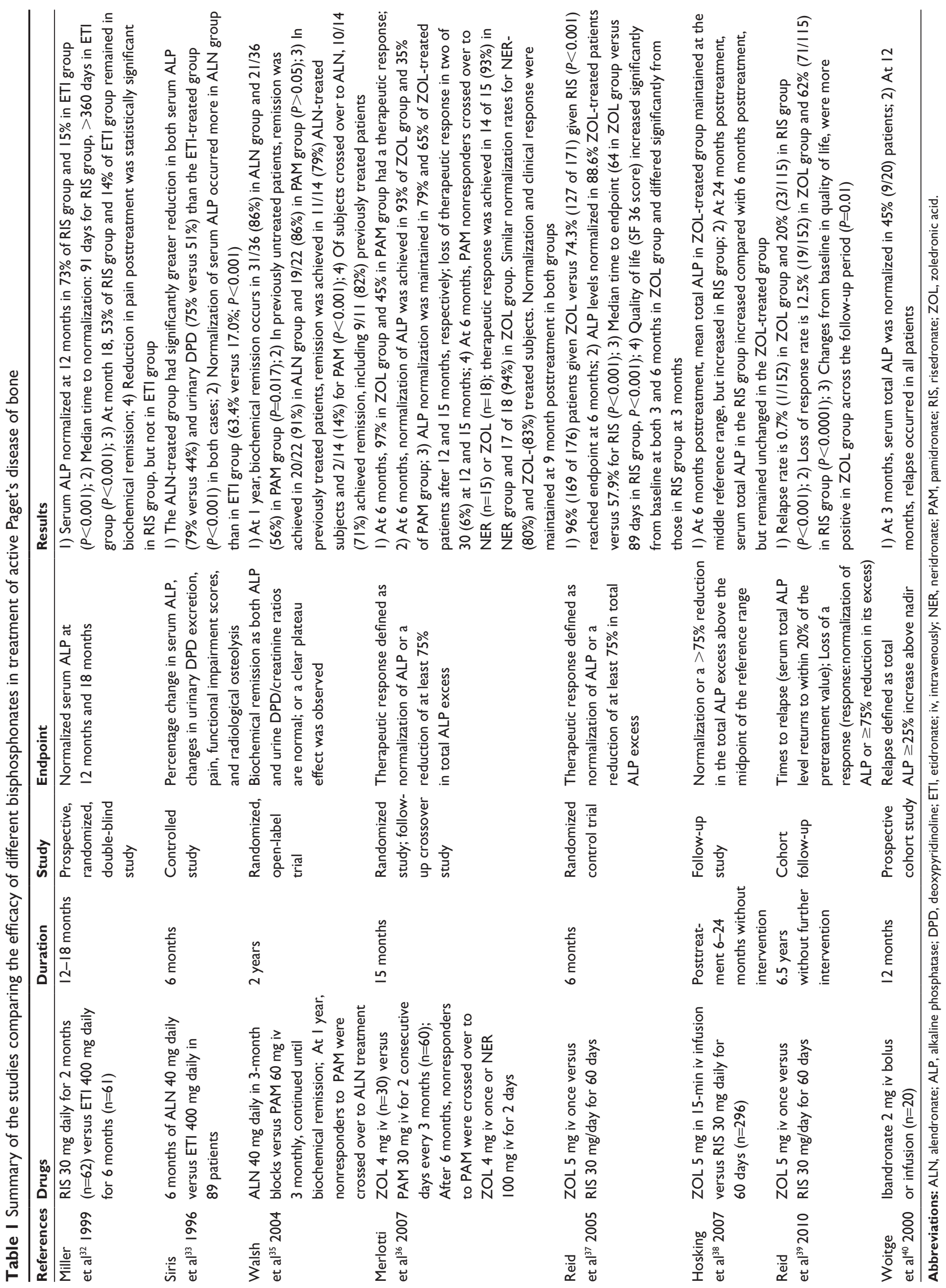


for treating Paget's disease of bone. Nevertheless, fair comparison of the efficacy across all bisphosphonates is invalid as these trials are not head-to-head comparisons, and the disease activities of the subjects as well as the regimes of medications varied among studies. In general, the nitrogencontaining bisphosphonates have been shown to achieve high biochemical remission rates, ranging from around 75\%-95\% at 6-12 months posttreatment with different regimes. One can always try another bisphosphonate for nonresponders as small crossover studies have shown positive results. Zoledronate seems to be the most attractive option among all, as a single intravenous dose has been shown to achieve normalization of serum ALP level in more than $90 \%$ of cases at 6 months posttreatment and nearly $80 \%$ at 12 months. ${ }^{36}$ The other advantages are the avoidance of drug noncompliance and gastrointestinal side effects related to oral bisphosphonates, which are common in the elderly.

\section{Side effects of bisphosphonates}

It is well recognized that proper selection of bisphosphonates enhances individual compliance, as oral and intravenous bisphosphonates have slightly different side effect profiles.

Upper gastrointestinal irritation and esophagitis, which occurs in $20 \%-30 \%$ of users are common side effects of oral bisphosphonates ${ }^{41}$ while acute phase response or flulike illness, which occurs in around $30 \%$ of those receiving the first infusion of zoledronate, is the most common one for intravenous amino-bisphosphonates. ${ }^{41}$ Symptomatic hypocalcemia can also occur when zoledronate is given to vitamin D-insufficient patients. Vitamin D and calcium supplement prior to or during the first few weeks following treatment is recommended for high risk group. ${ }^{42}$

For the past decade, there have been two rare but severe side effects reported, possibly related to the use of bisphosphonates. They are atypical subtrochanteric femoral fractures and osteonecrosis of the jaw (ONJ), which mainly develop in patients with osteoporosis and cancers treated with bisphosphonates.

Although case reports ${ }^{43-45}$ raised the plausible relationship between the use of bisphosphonates and the occurrence of atypical subtrochanteric femoral fractures in patients with osteoporosis, several retrospective analyses of clinical trials and large databases failed to show a significant increase in the total number of subtrochanteric fractures in the drug users. ${ }^{46-50}$ While it is obvious that the balance of risk and benefit is strongly in favor of the use of bisphosphonates in the osteoporotic population for prevention of osteoporotic fractures, ${ }^{47,51,52}$ its safety profile in treating Paget's disease of bone remains unknown due to the lack of data in this patient group and the differences in the dosages and regimes used (Table 2). So far, there are no reported cases of atypical femoral fracture in bisphosphonate users with Paget's disease of bone.

ONJ is another rare but serious side effect that is thought to be related to bisphosphonates, especially when used at high dose and intravenously to treat hypercalcemia in patients with malignancy. ${ }^{53}$ The majority of the reported cases are associated with dental procedures such as tooth extraction, or with preexisting dental diseases. Other risk factors for ONJ include concurrent malignancy, chemotherapy, radiotherapy, corticosteroid treatment, poor oral hygiene, and local infection including osteomyelitis. ONJ has been estimated to occur in $1 \%-10 \%$ of patients treated with intravenous bisphosphonates in cancer regimens and about $1 / 10,000-1 / 100,000$ patient-years in osteoporosis doses. ${ }^{54}$ The risk of ONJ in patients with Paget's disease of bone treated with bisphosphonates is unknown. In a systemic review of bisphosphonates-related ONJ, only three out of $368(0.8 \%)$ reported cases occurred in patients with Paget's disease of bone..$^{53}$ From the current data, it is expected that

Table 2 The bisphosphonate regimes for Paget's disease of bone, osteoporosis, and hypercalcemia in malignancy

\begin{tabular}{|c|c|c|c|}
\hline Drug name & $\begin{array}{l}\text { Regimen for Paget's } \\
\text { disease of bone }\end{array}$ & $\begin{array}{l}\text { Regimen } \\
\text { for osteoporosis }\end{array}$ & $\begin{array}{l}\text { Regime for malignancy related } \\
\text { hypercalcemia }\end{array}$ \\
\hline \multicolumn{4}{|l|}{ Oral } \\
\hline Etidronate & $400 \mathrm{mg} /$ day $\times 3-6$ months & $\begin{array}{l}400 \mathrm{mg} / \text { day } \times 2 \text { weeks, followed by elemental } \\
\text { calcium } 500 \mathrm{mg} / \text { day } \times 10 \text { weeks }\end{array}$ & $\mathrm{n} / \mathrm{a}$ \\
\hline Alendronate & $40 \mathrm{mg} /$ day $\times 6$ months & $10 \mathrm{mg} /$ day & $\mathrm{n} / \mathrm{a}$ \\
\hline Risedronate & $30 \mathrm{mg} /$ day $\times 2$ months & $5 \mathrm{mg} /$ day & $\mathrm{n} / \mathrm{a}$ \\
\hline \multicolumn{4}{|l|}{ Intravenous } \\
\hline Pamidronate & $60 \mathrm{mg} /$ day $\times 3$ days & $\mathrm{n} / \mathrm{a}$ & $90 \mathrm{mg} / 3-4$ weeks \\
\hline Ibandronate & $6 \mathrm{mg} /$ day $\times 2$ days & $3 \mathrm{mg} / 3$ months & $\mathrm{n} / \mathrm{a}$ \\
\hline Zoledronic acid & $5 \mathrm{mg}$ one dose & $5 \mathrm{mg} /$ year & $4 \mathrm{mg} / 3-4$ weeks \\
\hline
\end{tabular}

Abbreviation: $\mathrm{n} / \mathrm{a}$, not available. 
the risk of developing ONJ remains very low in patients with Paget's disease of bone treated with bisphosphonates, as the drug dosage is much lower than in cancer regimes, and treatment is usually intermittent. In spite of that, it is advisable to remind patients to perform all invasive dental procedures before starting bisphosphonates.

\section{Other medications}

As bisphosphonates may take weeks to suppress the excessive bone turnover and reduce bone pain caused by the pagetic lesion, opioid analgesics and nonsteroidal anti-inflammatory drugs can be used to provide faster and more effective pain relief.

Denosumab, a monoclonal antibody that inhibits osteoclastic bone resorption by binding to osteoblast-produced RANKL, has been suggested by a few case reports to be effective in controlling disease activity that is refractory to bisphosphonates. ${ }^{55,56}$ More data is warranted for its use in Paget's disease of bone.

Calcitonin in injection form has been used to treat Paget's disease of bone long before the arrival of the potent bisphosphonates. Its long-term use, however, is limited by the side effects of nausea, flushing, tachyphylaxis, and increased risk of malignancy. Presently, it is rarely used and is reserved only for those not tolerant of the more effective bisphosphonate therapy. Its use in Paget's disease of bone is advised to be limited to up to 3 months or 6 months in exceptional circumstances, such as for patients with impending pathological fractures. ${ }^{57}$ It has been reported to cause an approximately 50\% reduction in serum total ALP and relieve some symptoms such as alleviating bone pain, healing of osteolytic lesions, and reducing neurological complications. ${ }^{58}$ It is usually given at a daily dose of $100 \mathrm{IU}$ subcutaneously and subsequently reduced to a maintenance dose of 50-100 IU three times per week.

\section{Summary}

For the past two decades, the advent of nitrogen-containing bisphosphonates have allowed more effective treatment to suppress the excessive bone turnover in patients with Paget's disease of bone. The risks of developing two possible side effects of bisphosphonates, namely ONJ and atypical femoral fracture, are unknown but expected to remain very low as the regimes and dosages used are different from those in reported cases. Nevertheless, due to the lack of supporting evidence to treatment benefits, the decision to treat asymptomatic patients should be individualized with careful balance of risks and benefits.

\section{Disclosure}

The author reports no conflicts of interest in this work.

\section{References}

1. Paget J. On a form of chronic inflammation of bones (osteitis deformans). Med Chir Trans. 1877;60:37-64.9.

2. Kanis JA. Pathophysiology and Treatment of Paget's Disease of Bone. 2nd ed. London: Martin Dunitz; 1998.

3. Gennari L, Merlotti D, Martini G, Nuti R. Paget's disease of bone in Italy. J Bone Miner Res. 2006;21(Supp1 2):14-21.

4. Davie M, Davies M, Francis R, Fraser W, Hosking D, Tansley R. Paget's disease of bone: a review of 889 patients. Bone. 1999;24 (5 Suppl):11S-12S.

5. Hosking D, Meunier PJ, Ringe JD, Reginster JY, Gennari C. Paget's disease of bone: diagnosis and management. BMJ. 1996;312(7029): 491-494.

6. Carter LC. Paget's disease: important features for the general practitioner. Compendium. 1990;11(11):662, 664-665, 668.

7. Rousière M, Michou L, Cornélis F, Orcel P. Paget's disease of bone. Best Pract Res Clin Rheumatol. 2003;17(6):1019-1041.

8. Fraser WD. Paget's disease of bone. Curr Opin Rheumatol. 1997; 9(4):347-354.

9. Ralston SH, Digiovine FS, Gallacher SJ, Boyle IT, Duff GW. Failure to detect paramyxovirus sequences in Paget's disease of bone using the polymerase chain reaction. J Bone Miner Res. 1991;6(11): $1243-1248$.

10. Birch MA, Taylor W, Fraser WD, Ralston SH, Hart CA, Gallagher JA. Absence of paramyxovirus RNA in cultures of pagetic bone cells and in pagetic bone. J Bone Miner Res. 1994;9(1):11-16.

11. Helfrich MH, Hobson RP, Grabowski PS, et al. A negative search for a paramyxoviral etiology of Paget's disease of bone: molecular, immunological, and ultrastructural studies in UK patients. J Bone Miner Res. 2000;15(12):2315-2329.

12. Gherardi G, Lo Cascio V, Bonucci E. Fine structure of nuclei and cytoplasm of osteoclasts in Paget's disease of bone. Histopathology. 1980;4(1):63-74.

13. Mii Y, Miyauchi Y, Honoki K, et al. Electron microscopic evidence of a viral nature for osteoclast inclusions in Paget's disease of bone. Virchows Arch. 1994;424(1):99-104.

14. Gordon MT, Mee AP, Anderson DC, Sharpe PT. Canine distemper virus transcripts sequenced from pagetic bone. Bone Miner. 1992; 19(2):159-174.

15. Durán A, Serrano M,Leitges M, et al. The atypical PKC-interacting protein p62 is an important mediator of RANK-activated osteoclastogenesis. Dev Cell. 2004;6(2):303-309.

16. Rea SL, Walsh JP, Ward L, et al. A novel mutation (K378X) in the sequestosome 1 gene associated with increased NF-kappaB signaling and Paget's disease of bone with a severe phenotype. J Bone Miner Res. 2006;21(7):1136-1145.

17. Layfield R, Searle MS. Disruption of ubiquitin-mediated processes in diseases of the brain and bone. Biochem Soc Trans. 2008;36 (Pt 3):469-471.

18. Layfield R. The molecular pathogenesis of Paget disease of bone. Expert Rev Mol Med. 2007;9(27):1-13.

19. Whyte MP, Obrecht SE, Finnegan PM, et al. Osteoprotegerin deficiency and juvenile Paget's disease. N Engl J Med. 2002;347(3): 175-184.

20. Altman RD, Bloch DA, Hochberg MC, Murphy WA. Prevalence of Paget's disease of bone in the United States. J Bone Miner Res. 2000;15(3):461-465.

21. Detheridge FM, Guyer PB, Barker DJ. European distribution of Paget's disease of bone. Br Med J (Clin Res Ed). 1982;285(6347): $1005-1008$.

22. Wat WZ, Cheung WS, Lau TW. A case series of Paget's disease of bone in Chinese. Hong Kong Med J. 2013;19(3):242-248. 
23. Poór G, Donáth J, Fornet B, Cooper C. Epidemiology of Paget's disease in Europe: the prevalence is decreasing. J Bone Miner Res. 2006; 21(10):1545-1549.

24. Cundy T. Is Paget's disease of bone disappearing? Skeletal Radiol. 2006;35(6):350-351.

25. Shaker JL. Paget's disease of bone: a review of epidemiology, pathophysiology and management. Ther Adv Musculoskelet Dis. 2009;1(2):107-125.

26. Ralston SH. Clinical practice. Paget's disease of bone. N Engl J Med. 2013;368(7):644-650.

27. Doyle FH, Banks LM, Pennock JM. Radiologic observations on bone resorption in Paget's disease. Arthritis Rheum. 1980;23(10): $1205-1214$.

28. Langston AL, Campbell MK, Fraser WD, MacLennan GS, Selby PL, Ralston SH; PRISM Trial Group. Randomized trial of intensive bisphosphonate treatment versus symptomatic management in Paget's disease of bone. J Bone Miner Res. 2010;25(1):20-31.

29. Reid IR, Cundy T, Bolland MJ, Grey A. Response to publication of PRISM trial. J Bone Miner Res. 2010;25(6):1463-1464; author reply 1465.

30. Current Controlled Trials. Zoledronate in the Prevention of Paget's: the ZiPP study ISRCTN11616770 [webpage on the Internet]. London: Current Controlled Trials; 2008 [updated June 26, 2012]. Available from: http://www.controlled-trials.com/ISRCTN11616770. Accessed September 23, 2014.

31. Widler L, Jaeggi KA, Glatt M, et al. Highly potent geminal bisphosphonates. From pamidronate disodium (Aredia) to zoledronic acid (Zometa). J Med Chem. 2002;45(17):3721-3738.

32. Miller PD, Brown JP, Siris ES, Hoseyni MS, Axelrod DW, Bekker PJ. A randomized, double-blind comparison of risedronate and etidronate in the treatment of Paget's disease of bone. Paget's Risedronate/Etidronate Study Group. Am J Med. 1999;106(5):513-520.

33. Siris E, Weinstein RS, Altman R, et al. Comparative study of alendronate versus etidronate for the treatment of Paget's disease of bone. J Clin Endocrinol Metab. 1996;81(3):961-967.

34. Papapoulos SE, Eekhoff EM, Zwinderman AH. Acquired resistance to bisphosphonates in Paget's disease of bone. J Bone Miner Res. 2006;21(Suppl 2):88-91.

35. Walsh JP, Ward LC, Stewart GO, et al. A randomized clinical trial comparing oral alendronate and intravenous pamidronate for the treatment of Paget's disease of bone. Bone. 2004;34(4):747-754.

36. Merlotti D, Gennari L, Martini G, et al. Comparison of different intravenous bisphosphonate regimens for Paget's disease of bone. J Bone Miner Res. 2007;22(10):1510-1517.

37. Reid IR, Miller P, Lyles K, et al. Comparison of a single infusion of zoledronic acid with risedronate for Paget's disease. $N$ Engl J Med. 2005;353(9):898-908.

38. Hosking D, Lyles K, Brown JP, et al. Long-term control of bone turnover in Paget's disease with zoledronic acid and risedronate. J Bone Miner Res. 2007;22(1):142-148.

39. Reid I, Lyles KW, Su G, et al. Long-term efficacy of zoledronic acid compared with risedronate in Paget's disease. Bone. 2010;47 (Suppl 1):OC21.

40. Woitge HW, Oberwittler H, Heichel S, Grauer A, Ziegler R, Seibel MJ. Short- and long-term effects of ibandronate treatment on bone turnover in Paget disease of bone. Clin Chem. 2000;46(5):684-690.

Therapeutics and Clinical Risk Management

\section{Publish your work in this journal}

Therapeutics and Clinical Risk Management is an international, peerreviewed journal of clinical therapeutics and risk management, focusing on concise rapid reporting of clinical studies in all therapeutic areas, outcomes, safety, and programs for the effective, safe, and sustained use of medicines. This journal is indexed on PubMed Central, CAS,
41. Reid IR. Osteoporosis treatment: focus on safety. Eur J Intern Med. 2013;24(8):691-697.

42. Aclasta ${ }^{\mathrm{TM}}$ (zoledronic acid) [package insert]. Basel: Novartis; 2011.

43. Kwek EB, Goh SK, Koh JS, Png MA, Howe TS. An emerging pattern of subtrochanteric stress fractures: a long-term complication of alendronate therapy? Injury. 2008;39(2):224-231.

44. Lenart BA, Lorich DG, Lane JM. Atypical fractures of the femoral diaphysis in postmenopausal women taking alendronate. $N$ Engl J Med. 2008;358(12):1304-1306

45. Feldman F. Atypical diaphyseal femoral fractures - new aspects. Skeletal Radiol. 2012;41(1):75-81.

46. Park-Wyllie LY, Mamdani MM, Juurlink DN, et al. Bisphosphonate use and the risk of subtrochanteric or femoral shaft fractures in older women. JAMA. 2011;305(8):783-789.

47. Black DM, Kelly MP, Genant HK, et al; Fracture Intervention Trial Steering Committee; HORIZON Pivotal Fracture Trial Steering Committee. Bisphosphonates and fractures of the subtrochanteric or diaphyseal femur. N Engl J Med. 2010;362(19):1761-1771.

48. Nieves JW, Bilezikian JP, Lane JM, et al. Fragility fractures of the hip and femur: incidence and patient characteristics. Osteoporos Int. 2010;21(3):399-408.

49. Abrahamsen B, Eiken P, Eastell R. Subtrochanteric and diaphyseal femur fractures in patients treated with alendronate: a register-based national cohort study. J Bone Miner Res. 2009;24(6):1095-1102.

50. Abrahamsen B, Eiken P, Eastell R. Cumulative alendronate dose and the long-term absolute risk of subtrochanteric and diaphyseal femur fractures: a register-based national cohort analysis. J Clin Endocrinol Metab. 2010;95(12):5258-5265.

51. Meier RP, Perneger TV, Stern R, Rizzoli R, Peter RE. Increasing occurrence of atypical femoral fractures associated with bisphosphonate use. Arch Intern Med. 2012;172(12):930-936.

52. Dell RM, Adams AL, Greene DF, et al. Incidence of atypical nontraumatic diaphyseal fractures of the femur. J Bone Miner Res. 2012; 27(12):2544-2550.

53. Woo SB, Hellstein JW, Kalmar JR. Narrative [corrected] review: bisphosphonates and osteonecrosis of the jaws. Ann Intern Med. 2006;144(10):753-761.

54. Khosla S, Burr D, Cauley J, et al; American Society for Bone and Mineral Research. Bisphosphonate-associated osteonecrosis of the jaw: report of a task force of the American Society for Bone and Mineral Research. J Bone Miner Res. 2007;22(10):1479-1491.

55. Schwarz P, Rasmussen AQ, Kvist TM, Andersen UB, Jørgensen NR. Paget's disease of the bone after treatment with Denosumab: a case report. Bone. 2012;50(5):1023-1025.

56. Grasemann C, Schündeln MM, Hövel M, et al. Effects of RANKligand antibody (denosumab) treatment on bone turnover markers in a girl with juvenile Paget's disease. J Clin Endocrinol Metab. 2013; 98(8):3121-3126.

57. European Medicines Agency. European Medicines Agency recommends limiting long-term use of calcitonin medicines [press release]. London: European Medicines Agency; 2012 [July 20]. Available from: http://www.ema.europa.eu/docs/en_GB/document_library/Press_ release/2012/07/WC500130122.pdf. Accessed September 23, 2014.

58. Levy F, Muff R, Dotti-Sigrist S, Dambacher MA, Fischer JA. Formation of neutralizing antibodies during intranasal synthetic salmon calcitonin treatment of Paget's disease. J Clin Endocrinol Metab. 1988;67(3):541-545. 